\title{
Kurıkanların Türk Tarihindeki Yeri ve Önemi
}

\section{Importance and Role of Kurykan People In Turkic History}

\author{
Elvin YILDIRIM ${ }^{1}$
}

'Sorumlu yazar/Corresponding author: Elvin Yıldırım (Dr. Öğr. Üyesi), Istanbul Aydın Üniversitesi, Fen Edebiyat Fakültesi Tarih Bölümü, İstanbul, Türkiye E-posta: elvinyildirim34@gmail.com ORCID: 0000-0001-7529-1875

Başvuru/Submitted: 05.03 .2020 Revizyon Talebi/Revision Requested: 06.03.2020

Son Revizyon/Last Revision Received: 13.03.2020

Kabul/Accepted: 03.04.2020

Online Yayın/Published Online: 03.06.2020

Atıf/Citation: Yildirim, Elvin. "Kurıkanların Türk Tarihindeki Yeri ve Önemi." Türkiyat MecmuasıJournal of Turkology 30, 1 (2020): 287-302. https://doi.org/10.26650/iuturkiyat.699234

\section{öz}

Orhun Abidelerinden Bilge Kağan ve Kültigin Yazıtları'nda bazen düşman bazen de kağanlarının ölümü üzerine yas tutan millet ve boylar arasında zikredilen Kurıkanlar, Baykal Gölü'nün batı yönünde oturan konar-göçer boylardan idiler. Onlardan kalan dil bakiyeleri arasında Lena ve Angara'da ortaya çıkarılmış ve Göktürk alfabesi ile yazılmış metinler mevcut idi. Türk tarihinin erken dönemleri için başvuru kaynaklarımızdan olan Çin kaynaklarında Gulikan veya Ku-likan etnosu ile kaydedilmiş olan ve İslam Kaynaklarında Furi veya Kuri olarak geçen toplulukla özdeşleştirilen, atlarının güzelliği ile nam salmış olan bu Türk topluluğu, Yakutların ve Buryatların bazen de Moğol kabilelerinden Horların ataları oldukları konusunda tartışılmışlardır. Bu makalede Baykal ve çevresinde meskûn olan, hayvancilık ve özellikle at yetiştiricisi ve demirci olan, bir seferde beş bin asker çıkarabilme özelliğine sahip, Kurumçi Kültürü'nü meydana getirerek arkalarında oldukça önemli maddi kültür kalıntıları bırakan Yakutların ataları Kurıkanların yazılı ve arkeolojik kaynaklardaki durumları irdelenecek ve bıraktıkları maddi kültür unsurları çerçevesinde Türk tarihindeki önemi ve yeri üzerinde durulacaktır.

Anahtar kelimeler: Kurıkanlar, Yakutlar, Baykal, Kurumçi Kültürü, Şişkin Petroglifleri

\section{ABSTRACT}

The Kurykan people were seen for the first time in the mourning ceremony of the Turk kagan and were recorded in the Orkhun Inscriptions. They were one of the nomadic tribes spread on the west side of Baikal Lake and they were known as both enemy and friend. It is very interesting that runic texts of the Kurykan were found in Lena and Angara. The Kurykan people were recorded as Gulikan or Ku-li-kan by the Chinese which is one of primary sources for early Turkic history. They were identified as Furi or Kuri people from Islamic sources. Historical sources recorded that they were renowned for their beautiful horses. There are three main opinions about them: They are accepted as ancestors of the Yakut, Buriat, or Mongolian Khor tribe. In this article, we recognize them as ancestors of the Yakuts. They lived in Baikal and its surrounding area, practiced animal husbandry and were horse breeders. They were also good blacksmiths. They had an army of five thousand soldiers to show their strength and power. They created the Kurumchi Culture and left behind especially important cultural materials. These topics will be examined according to material cultural elements and their importance in Turkic history will be emphasized.

Keywords: Kurykans, Yakuts, Baikal, Kurumchi Culture, Petroglyphs Siskin 


\section{EXTENDED ABSTRACT}

The exploration of material cultural elements which belonged to a people who lived a nomadic life and practiced animal husbandry on the shores of Baikal Lake is very important. These people are the Kurykans of the Baikal region, but today they live in different places. Originally, they had an economical system based on hunting, fishing, and reindeer feeding. According to some elements recorded in the Yakut Eposes, we understand that they immigrated from the Baikal Lake region. Archeological studies done in the territories of Upper Lena and Angara found material cultural relics of the Kurykan people which became known as the Kurumchi Culture. Kurumchi cultural elements spread to the regions of Barguzin, Tunkin, Angara, Balagan and its lower lands, upper Lena, and Jigalova. There are some opinions that the Kurumchi culture belonged the Mongolian Khor people, and archeologists say that the Kurumchi Culture was created by a people called "Gulikan"/ "Kulikan" by Chinese sources and "Uç Kurıkan" of Bilge Kagan and Kultigin inscriptions, namely Kurykans. According to these sources, the Kurykan tribe lived on the shores of Baikal Lake, spoke Turkic. had beautiful horses, and lived a nomadic life. There is some research which emphasizes the aligning of the Kurykan name with "Kuri" and "Furi" from Islamic sources, but there is no information about the "Kuri" or "Furi" tribe. In addition, wehave no clear historical records about the Kuri or Furi. According to the "Kyrgyz" chapter of the $10^{\text {th }}$ century book Hudud al Alam, the "Kuri" tribe was a vassal tribe of the Kyrgyz. They were living east of the Kyrgyz, but they did not mix with the Kyrgyz tribe. According to sources, they were a very brutal people, even eating human flesh. The Kyrgyz tribe did not understand thethe Kuri language. However, there are opinions that state the Kurykan tribes entered an ethno-political union with the Kyrgyz. The Kurykan people were recorded as both an enemy and a friend tribe. They attended the mourning ceremony of Bilge Kagan and that showed their friendship. The Kurykan were recorded as "Uç Kurikan" in Turkic inscription. It was recorded that they had two "erkin" (an old Turkic chief title) according to Chinese sources. At one time, they had five thousand soldiers who had fighting power. According to Xin Tang Shu, the "Kurykan" people originated from Ding-ling/ Gao-che stock and they spoke the Turkic language. Ding-ling/Gao-che tribes were Turkic. Runic inscriptions were discovered in the eighteen places where the Kurykan lived. In addition, runic writings were found on the border of Yakutia. Although it is stated that they spoke the Turkic language and had their own runic writing (map 2), there are some who believe that they were ancestors of the Buryat-Khongorof and Khoro-Mongol tribe. It is claimed that the Kyrykan were the Kuri or Furi from Islamic sources and ancestors of the Mongolian Khors, so they were a Mongolian tribe. However, as we know, they were related to the tribes of Xianbei and Turkic peoples were living on the Kurykan's original lands in ancient times. With the arrival of Mongolian tribes to the Baikal area, the Turkic speaking tribes came under the domination of a new language. In this regard, it is quite natural to see the Turkish Kurykan traditions in the traditions and customs of the Buryats who appeared in that region later. The appearence 
of the Mongolian tribes and the emergence of the Buryats in the region are dated to the $14^{\text {th }}$ century. The Kurykan people, on the other hand, dominated the region for hundreds of years before the Buryats emerged. However, with the begining of the spead of the Mongolians, the Kurykan tribes immigrated to today's Yakut lands. Since the Yakuts expressed themselves as Urankhai people, there may be connections between the ethnicity of Urankhai and the ethnicity of Kurykan. The Yakuts used the runic writings and tamga shapes of their ancestors from the $14^{\text {th }}$ and up to the $17^{\text {th }}$ century. It is seen that they used runic writings and tamga shapes until the $21^{\text {st }}$ century. Although they lived in an area that was very far from China, they sent ambassadors to the Chinese palace in 647 . We can see they were good warriors because of the many rock painting of horsemen and hunting scenes left from them. The surveillance fortifications around Lake Baikal are the most important relics of the Kurykan people. The Siskin rock paintings are their most significant artistic works. This area is considered a cult area where the Kurykan worshipped. The Kurykans were linked to the Tingling people who were clearly a Turkic tribal union. Their material culture can be accepted as Turkic material culture, moreover their runic writings are the same as Turkic writings. Islamic sources stated that they could not understand the Kyrgyz language. It was quite natural because they were living far away. They were ancestors of the Turkic-speaking Yakuts who speak a different Turkic dialect which most Turkic people cannot understand. The Kurykan and Kurumchi Culture have been preserved by the Turkic Yakuts in the area which can be considered as the northernmost lands of the Turks or Turkistan nowadays. 


\section{Giriş}

Baykal Gölü kıyılarında hayvancılıkla uğraşan ve konar göçer yaşam süren -konar göçer yaşam stili kaya resimleri sanatına da yansımıştır (Resim 4)- bir topluluğa ait maddi kültür unsurlarının keşfedilmesi oldukça ilgi çekmiştir çünkü genel olarak bu sahada avcılık, balıkçılık ve ren geyiği üzerine ekonomik bir yapılanma mevcut idi. ${ }^{1}$ XVIII. yy.'ın ortalarında Miller ve Gmelin'in, Yakut destanlarındaki folklorun Baykal çevresinde geliştiğine dair emareler tespit etmeleri üzerine dikkatlerini buraya çevirmişlerdir. Yer adlarının benzerliğine göre Yakutların $^{3}$ ataları Baykal bölgesinde yaşamış olmalı hatta daha eskileri Yenisey bölgesinde bulunmalıydılar. ${ }^{4}$ Tüm bu ifadelerden yola çıkarak M. P. Ovçinnikov, Yakutların erken atalarının Üst Lena ve Angara havalisinde maddi kültür bakiyeleri -Kurumçi Kültürü- bırakan topluluğa dikkat çekmiştir. ${ }^{5}$ Kurumçi Kültürü’nü bırakanların Moğol boylarından sayılan Horlar mı yoksa Kurıkanlar mı oldukları iddiaları bulunsa da söz konusu kültür bakiyelerinin Kurıkanlar tarafından oluşturulduğu başta Okladnikov olmak üzere arkeologlar tarafından ortaya konulmuştur.

\section{Yöntem}

Bu çalışmada Türklerin meskûn oldukları Baykal Gölü çevresi ve günümüz Yakutistan toprakları boyunca Lena ve Selenga nehirleri etrafında maddi kültür unsurları bırakmış olan, Orhun Yazıtları'nda Kurıkan/Üç Kurıkan adıyla, Çin kaynaklarında ise Guligan olarak zikredilen Türk boyu ve onların geride bıraktıkları maddi kültür dönemi hakkında yapılmış araştırma sonuçları incelenmiştir.

1 Baykal bölgesine göçen Yakutların ataları -Kurıkanlar- Gumilev'e göre XI. yy.'da Lena Vadisine gelmişlerdir. Nehir ve subasar alanlarını kullanarak, önceki bozkır hayatını taklit etmek suretiyle bozkır cinsi atlar yetiştirdiler. Ama geyik yetiştiricisi Evenklerin kendilerine sundukları gür ormanların su ayrım noktalarına hiç yaklaşmadılar. Kurıkanlar hayvancılığın yanısıra tarım, balıkçılık, avcılık ve at yetiştiriciliği ile de uğraşmaktaydılar. Bk. İ. V. Aseev, Pribaykalye v Sredine Veka (po arheologiçeskim dannım), (Novosibirsk: İzdatelstvo Nauka, 1980), 136. Bk. L. N. Gumilev, Avrasyadan Makaleler I, çev. Ahsen Batur, (İstanbul: Selenge Yayınları, 2006), 97.

2 Seroşevsky, Sahaların güney kökenleri üzerine yaptığı çalışmasında 1800'lerin sonlarında derlenen Yakut destanlarında onların şimdi meskûn olan sahaya göç ettiklerini fakat tam olarak nereden göç ettiklerinin tespit edilmesinin zor olsa da onların güneyden kuzeye doğru göç ettiklerini ifade etmektedir. Destanlardaki motifler ve eski güney bölgesindeki yaşamlarından kalan dil bakiyeleri bu durumun en önemli işareti olduğunu belirterek, Saha dilinde bulunan ve kendi yaşam sahalarında olmamasına rağmen, destanlarda var olan Türkçe hayvan adlarının, iklim ve bitki adları onların güney menşeili olduklarını göstermesi bakımından önemlidir. Bk. V. L. Seroşevsky, Saka Yakutlar, çev. Arif Acaloğlu, (İstanbul: Selenge Yayınları, 2007), 25-48.; Narodı Sibiri, ed. M. G. Levin ve L. P. Potapov, (Moskva-Leningrad: İzdatelstvo Akademii Nauk SSSR, 1956), 270. Bununla birlikte güney topraklarından geldikleri ve bu güney yönünün neresi olduğu muallakta olduğu gibi, onların Yenisey bölgesinden Lena Havzasına geldikleri de ifade edilmektedir. Bk. N. A. Aristov, Türk Halklarının Etnik Yapısı, çev. Ahsen Batur, (İstanbul: Selenge Yayınları, 2014), 86-87.

3 Yakutların atalarına dair mesele oldukça karışık olmakla birlikte onların köklerinin güneyden geldikleri açıktır. Bununla birlikte Türk lehçesi konuşan Yakutlarla Türkler pek çok bakımdan da benzerlik göstermektedirler. Bunlar kendilerini maddi kültür bakiyelerinde göstermektedir. Misal olarak deri eşyaları, Kımız ve yağ hazırlamaları, koşum ve eyer takımları vb. bk. S. A. Tokarev-I. S. Gurviç, "The Yakuts”, The People Of Siberia, ed. M. G. Levin- L. P. Potapov, (Chicago-London: The University Of Chicago Press, 1964), 245.

4 Seroşevsky, Saka Yakutlar, 37.

5 A. P. Okladnikov, Ístoriyii i Kulturı Buryatii, (Ulan-Ude: Buryatskoye Knijnoye İzdatelstvo, 1976), 22. 
İnceleme yapılırken söz konusu döneme ait kaya resimleri, runik yazılar ve yazılı kaynaklara dayanan araştırmalarda söz konusu döneme atfen yapılmış olan çıkarımlar tespit edilerek Kurıkanların bir Moğol boyu değil Türkçe konuşan bir Türk boyu olduğu üzerine bir değerlendirme yapılmıştır. Diğer bir taraftan söz konusu kaya resimleri ve runik yazılar ile ilgili görüş ve tartışmalara temas edilmemiş ve ilgili araştırma eserlerindeki genel kabul gören değerlendirmelere yer verilmiştir.

\section{Bulgular}

Baykal Gölü çevresinde ve Olhon Adası'nda kuzey istikametli bugünkü Yakutların yaşadıkları sahaya doğru hayvancılıkla uğraştığı tespit edilen ve özellikle kaya resimlerinden atın hayatlarında büyük bir öneme sahip olduğu görülen, Kurumçi Kültürü olarak adlandırılan bir döneme ait maddi kültür unsurlarının tespit edilmesiyle birlikte bu dönemin kimler tarafından oluşturulduğu sorusuna yanıtlar aranmaya başlanmıştır. Maddi kültür unsurlarından alınan kalıntılar üzerinde yapılan çalışmalar söz konusu bakiyelerin VI. ve X. yy. arasına tarihlendirildiğini ve yazılı kaynakların bu tarih aralığında, bu sahada Gulikan/Kurıkanlar olarak zikredilen boyun yaşadığını ve bu kültürün onlar tarafından ortaya koyulduğunu göstermiştir.

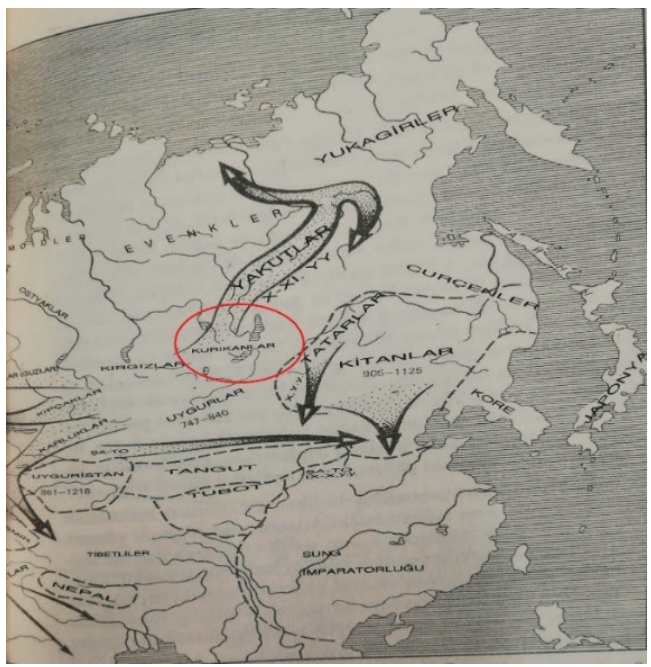

Harita 1: Kurıkanların Lena Havzası'nın yukarı akımlarına doğru geçişleri ve XI. yy.'da Buryatların ataları tarafindan mağlup edilmeleri sonrasında bugünkü Saha yurdu sınırlarına girip Yakutların ortaya çıkış süreci gösterilmektedir. ${ }^{6}$

Kurumçi Kültür dairesi içerisinde Göktürk alfabesi ile yazılmış kelimeler tespit edilmiştir. Bu kültür dairesi Selenge’nin akım yönünde Barguzin Havzası, Tunkin bölgesi, Angara Havzası'ndan Balagan ve biraz daha aşağısı, yukarı Lena ve Jigalova'ya kadar olan sahayı

6 Gumilev, Avrasyadan Makaleler-1, çev. Ahsen Batur, 146-147. 
kapsamaktadır. ${ }^{7}$ Ayrıca Baykal Gölü’nde bulunan Olhon Adası'nda da Kurumçi Kültürü8 (VI-X yy.) dönemine ait maddi kültür unsurları (Resim 1-2) mevcuttur. Kurumçi bakiyeleri üzerine yapılan incelemeler sonucunda, Çin kaynaklarına dayanarak bu bakiyelerin kaynaklarda Baykal (Han-hai) çevresinde yerleşik olan Ku-li-kanlara ait oldukları sonucuna ulaşılmıştır. ${ }^{9}$ Han-hai'nin kuzeyinde yaşayan Ku-li-kanlar, bazı kaynaklara göre Uygurların kuzeyinde bulunmaktadırlar ve beş bin yetişmiş asker çıkaracak güçtedirler. ${ }^{10}$ İslam kaynaklarında geçen Kuri veya Furileri Kurıkanlarla özdeşleştiren görüşler mevcuttur. ${ }^{11}$ Dilbilimciler Kuri ve Furi kelimesinin birbiri ile karıştırılabilecek yakınlıkta sesler olduklarını düşünerek sadece Kuri kabilesinin olduğu üzerinde durmuşlardır. Fakat bu kaynaklar Furi ${ }^{12}$ veya Kuri diye zikredilen bu kavim hakkında herhangi bir bilgi vermemekte, daha doğrusu güvenilir olmayan (insan yedikleri, acımasız oldukları, vahşi hayvanlara benzedikleri gibi) bilgiler vermektedirler. XIV. Asır İran müelliflerinden Raşit, Baykal bölgesinde Kuri adında bir halk olduğunu belirtmektedir. ${ }^{13}$ Kurıkanlar ve Kırgızlar arasında komşuluktan öte bir ilişki mevcut değildir. Her iki Türk boyu da hem Çin kaynaklarında hem de Türk yazıtlarında aynı anda zikredilmişlerdir. ${ }^{14}$ Bununla birlikte Kırgızlarla komşu olan Kurıkanların onların etno-siyasi birliğine dahil oldukları görüşleri de mevcuttur. ${ }^{15}$

\section{Tartışma}

Orhun Yazıtları'nın keşfi ve çözümlenmesi Türk Tarihi ve Türk diline dair pek çok meselenin halledilmesinde anahtar olarak kapalı olan pek çok kilidin açılmasını sağlamıştır. Bu bakımdan Ku-li-kan etnoniminin Orhun Yazıtları'nda zikredilen Kurıkanlar ${ }^{16}$ oldukları anlaşılmıştır. Kültigin Abidesi'nin doğu yüzü (4)'de Göktürk Kağanının vefatı dolayısıyla aralarında yasçı

7 Okladnikov, Istoriyii i Kulturı Buryatii, 23.

8 A. P. Okladnikov, "Drevnyaya Tyurkskaya Kultura v Verhovyah Lenı", Kratkiye Soobşeniya XIX, (1948), 7.; B. B. Dashibelov, İstoki: Ot drevnih Hori-Mongolov v Buryatam Oçerki, (Ulan-Ude: İzdatelstvo Buryatskogo Nauçnogo Tsentra SO RAN, 2003), 31.

9 Okladnikov, Istoriyii i Kulturı Buryatii, 50.

10 Ahmet Taşağıl, Çin kaynaklarına Göre Eski Türk Boyları (Ankara: TTK Yayınları, 2004), 88.

11 Ahmet Taşağıl, "Yakutlar", TDV İA, 43 (İstanbul: Türkiye Diyanet Vakfi, 2013), 295-296.

12 Gerdizi Zeyn el Ahbar'da Kırgız Ülkesinden yola çıktıktan sonra yolun üçe ayrıldığını, yolun birinin güneye Tokuz Oğuzlara, diğerinin Kimek ve Halluh (Karluk) tarafina üçüncü yolun ise çöle gittiğini, üç ay sonra Fûrî (Moğol Kabilelerinden) denen büyük bir kabileye varır. Bk. Ramazan Şeşen, İslam Coğrafyacılarına Göre Türkler (Ankara: TTK Yayınları, 2001), 77.; Hudud al Alam'de Kırgız Ülkesi bahsinde, "Furi (Kuri) kabilesi Kırgızlara bağlı bir kabile olup onların doğusunda yaşarlar ve diğer Kırgız kabileleri ile karışmazlar. Bunlar acımasızdır ve insan yerler. Diğer Kırgız kabileleri onların dilini anlamazlar.” şeklinde ifade edilmişlerdir. Bk. Hudūd al- 'Ālam 'The Regions Of The World', tran. and exp. V. Minorsky (London: 1937), 97.

13 Belek Soltonoyev, Kırgız Tarihi I-II, çev. M. Dıykanbayeva, (Ankara: Kömen Yayınları, 2018), 38.

14 Tarihi kaynaklarda Kırgız adı ve anlamı için bk. Mehmet Kıldıroğlu, Kırgızlar ve Kıpçaklar (Ankara: Türk Tarih Kurumu, 2013), 29.

15 Muratbek Kocabekov, “Kırgızların Sayan-Altay Bölgesindeki Komşuları”, SDÜ Fen Edebiyat Fakültesi Sosyal Bilimler Dergisi 36 (2015), 19.

16 Levin, Kurıkanların $\ddot{u} c ̧$ kuri kan (üç qurï qan) şeklinde transkript edilmesini gerektiğini belirtmektedir. Bk. G. G. Levin, Istoricheskiye Svyazi Yakutskogo Yazıka s Drevnetyurkskimi Yazıkami VII-IX vv. (V sravnitelnosopostavitelnom aspekte s vostochno-tyurkskimi i mongolskimi yazıkami), (Yakutsk: Izd-vo SVFU, 2013), 47. 
ve ağlayıcıların cenaze merasimine katılıp ağladıkları ve yas tuttukları ifade edilmiş, yas için gelen bağlı devlet ve boylar Bökli Çölli halk, Çin, Tibet, Avar, Bizans, Kırgız, Üç Kurıkan, Otuz Tatar, Kıtay ve Tatabılar olarak kaydedilmişlerdir. ${ }^{17}$ Cenaze merasimine yas için gelen Üç Kurıkanlar Kültigin Yazıtı'nın doğu yüzü (14) satırlarında “Güneyde Çin Halkı hep düşmanmış. Kuzeyde Baz Kağan Dokuz Oğuz halkı düşmanmış. Kırgızlar, Kurıkanlar, Otuz Tatarlar, Kitanlılar (ve) Tatavılar hep düşmanmış..."18 ifadesinden anlaşıldığı üzere düşman kabileler arasında da zikredilmiştir. Bilge Kağan Yazıtı Doğu (12) satırında da bu düşmanlık aynı şekilde ifade edilmiştir. ${ }^{19}$ Yazıtlarda hem Üç Kurıkan şeklinde hem de Kurıkan olarak ifade edilen bu Türk boyu Çin kayıtlarından bir tanesinde 2 erkinlik halinde bir arada oturmaktadırlar şekli ile kaydedilmişlerdir. ${ }^{20}$ Onların düşman kabileler arasında zikredilme sebebi savaşçı çıkarabilmelerinden kaynaklanıyor olabilir kanaatineyiz.

Bahaeddin Ögel, "Kurıkanların kuzey komşuları bugünkü Yakutlardı. Bu duruma göre, Kurıkanlar Altay ve Sayan dağlarından Yakut Ülkesi’ne kadar Türkçe konuşan kavimler arasında münasebet kuran, ortadaki bir Türk kavmi rolü oynuyorlardı"21 şeklindeki ifadesi ise tartışmaya açıktır. E. Pulleyblank Han hanedanı kaynaklarında Türkçe konuşan halkların üç grup atasının Gegunlar/Jiankunlar ${ }^{22}$, Ding-lingler ve Sirler olarak belirlendiğini, Ding-ling/ Kao-che soyundan gelenlerin Tiele kabileler birliğini kurduklarını ve ilk kez 630'da dokuz soyun belirtildiğini ifade etmiştir. Bu boylar Xin Tangshu' dan öğrenildiğine göre 1) Uygurlar 2) Sirler 3) Tuobalar 4) Kurıkanlar 5) Telengütler 6) Bukular 7) Bayırkular 8) Tongralar 9) Hunlar idiler. ${ }^{23}$ Xin Tangshu' daki tasnife göre Kurıkanlar Türkçe konuşmaktadır. Ayrıca geride bıraktıkları maddi kültür unsurlarında runik harfli yazılar mevcuttur. Ögel hocanın ifadesi kanaatimizce problemlidir. Birincisi onlar Yakutlar ile komşu değillerdi bizatihi ataları idiler. ${ }^{24}$ İkincisi ise Türk rolü oynamaları için herhangi bir sebebe ihtiyaçları yoktu. Başkente en uzak mesafede oturan bu topluluk Çin ile tek başına görüşme talebinde bulunup ${ }^{25}$ Çin İmparatoruna hediye atlar sunma cesaretini göstermişlerdir.

17 Erhan Aydın, Orhon Yazıtlarl, (İstanbul: Bilge Kültür Sanat, 2017), 52.

18 Aydin, Orhon Yazitlart, 55.

19 Aydın, Orhon Yazıtlarl, 84.

20 Taşağıl, Çin kaynaklarına Göre Eski Türk Boyları, 88.

21 Baheddin Ögel, Íslamiyetten Önce Türk Kültür Tarihi (Ankara: TTK Yayınları, 2003), 202.

22 Kirgızlar

23 S. G. Klyaştornıy, Kadim Avrasya nın Bozkır Imparatorlukları (İstanbul: Tek-Esin Vakfı Yayınları, 2018 ), 86. Ayrıca Bk. Edouard Chavaness, Çin Kaynaklarına Göre Batı Türkleri, çev. M. Koç (İstanbul: Selenge Yayınları, 2013), 129-130., Ömürkul Kareyev, Türkler ve Kağanlıklarl, çev. Mustafa Kalkan (İstanbul: Bilge Kültür Sanat Yayınları, 2008), 39.

24 Ksenefontov Yakutların oluşumunu üç ana döneme ayırmaktadır. Buna göre Moğol İstilasından önce ilk evrede Hunlar, ikinci evrede ise VII-VIII. Yy'da Angara'dan Baykal çevresine göçen Vilyuy Yakutlarının ataları olan Kurıkanlar bulunmuşlardır. G. B. Ksenefontov, Uranghay-Sahalar Oçerki Po Drevney İstoriyi Yakutov, T.I, (İrkutsk: Ogiz, 1937), 397. N. N. Kozmin, "K Voprosu o Vremeni Vodvoreniya Buryat Okolo Baykala", Sibirskaya Jivaya Starina, Vıp. III-IV., 1925, 118. N. N. Dikov, Bronzovly Vek Zabaykalya, Akademii Nauk SSSR, Ulan-Ude, 1958, 70.; L. N. Gumilev, Drevniye Tyurki, (Sankt Peterburg: İzdatelskii Dom Kristall, 2002) 70.; Narodı Sibiri, ed. M. G. Levin-L. P. Potapov, (Moskva-Leningrad: İzdatelstvo Akademii Nauk SSSR, 1956) 98.

25 Ahmet Taşağıl, Göktürkler II (Ankara: TTK Yayınları, 1999), 44. 
Kurıkanların Türkçe konuştukları kaynaklarda belirtilmiş olmasına rağmen ki kendilerine ait çok geniş bir sahada (Resim 2) runik yazılar bırakmışlardır, onların Buryat ${ }^{26}$-Hongorod ${ }^{27}$ ve de Horo-Moğol kabilesinin atası olduğu görüşleri ileri sürülmüştür. Kurıkan etnoniminin Kuda Buryatlarında korunmuş olan Horo-Mongol adındaki hor'dan geldiğ $\mathrm{i}^{28}$ fikirleri ileri sürülmüştür. Yukarıda da belirttiğimiz üzere İslam kaynaklarında Kuri veya Furi olarak zikredilmiş bu boyun kuri ve hori etnosunun aynı olduğu iddiaları üzerinde durmaktadırlar fakat kuri olarak zikredilen kabile Horlar değildir ve onlar Şiyenbiler ile ilişkilidirler. ${ }^{29}$ Bununla birlikte Moğol kabilelerinin özellikle Kurumçi Kültürüne atfedilen Hor ve Horilerin Baykal kıyılarına barışçıl yollarla gelmedikleri, bölgeye geldikten sonra Kurıkanların Lena'nın kuzeyine Yakut topraklarına ilerlediği açıktır. ${ }^{30}$ Bununla birlikte Horların Yakut etnogenezinde Horların payının olduğu, fakat Yakutların temel ataları olmadıkları, dil ve folklörlerine herhangi bir katkıda bulunmadıkları görüşü de mevcuttur. ${ }^{31}$ Sahalar kendilerini Urankhay kişi ${ }^{32}$ olarak tanıtmışlardır. Uranhay etnonimi ile kurıkan etnonimi arasında bağlantılar olabileceği ifade edilmektedir. $^{33}$

Bölgede kalan Moğollar ile Türk Kurıkanların temasları sonucunda dillerindeki sözlerin geçişinde ve gelenek göreneklerinin tesirinde kalmış olmaları da gayet olağandır. Konar göçer bozkır tipinin ağır bastığını gördüğümüz ve aynı zamanda savaşçı bir boy olan Kurıkanlar geldikleri bölgedeki avcı, balıkçı kabileler üzerinde hakimiyetini sağlamış ve zamanla bu

26 Baykal sahasına Moğol kabilelerinin gelmesi ile burada yaşayan ve Türkçe konuşan kabileler yeni bir dilin hakimiyeti altına girmişlerdir. Bu Moğol dilidir. Bu bakımdan bölgede daha sonra ortaya çıkan Buryatların gelenek ve göreneklerinde Türk Kurıkan geleneğinin görülmesi gayet doğaldır. Kozmin Moğol Kabilelerinin gelişi ile Buryatların ortaya çıkışını XIV yy.' a tarihlendirmektedir. Kozmin, "K Voprosu o Vremeni Vodvoreniya Buryat Okolo Baykala”128.; İmenohoev, Buryatların eski mezarlarında yaptığı incelemelerinde Kurıkanların etkisinin bulunduğunu belirtmektedir. Bk. N. V. İmenohoev, "Tipologiya Drevneburyatskih Zahoronenii (k Problemam Etnogeneza Buryat)", Etniçeskaya İstoriya i Kulturno-Bıtovlye Traditsii Haradov Baykalskogo Regiona, ed. B. B. Bazarov, (İrkutsk: İzdatelstvo Ottisk, 2010), 32.

27 B. B. Dashibelov, "O Hori Mongolah i Hordutah v Şamanskih Materialah M. N. Hangalova”, Etniçeskaya Ístoriya i Kulturno-Bitoviye Traditsii Haradov Baykalskogo Regiona, edit. B. B. Bazarov, (İrkutsk: İzdatelstvo Ottisk, 2010), 59.

28 B. B. Daşibelov, "Khunnu i Syanbi V Slozhenii Kulturı Khorı-Mongolov", Drevniye Kulturı Mongolii Mongolii i Baykalskoy Sibirii (Materialı Mejdunarodnoy Nauçnoy Konferentsii 20-23 Sentryabrya 2010 g.), edit. A. D. Tsybiktarov, Ulan-Ude: İzdatelstvo Buryatskogo Gosniversiteta, 2010), 192.

29 B. R. Zoriktuev, "O Proishojdeniyi Horintsev", Koçevyye İmperii Evrazii v Svete Arheologiçeskih i Mejdictsiplinarnıh Issledovanıy, edit. B. V. Bazarov, Kniga 2 (Ulan-Ude: İzdatelstvo BNTs SO RAN, 2019), 148.

30 İmenohoev, mezar gömü üslubunu arka plana atarak Kurumçi Kültürünü Horlara atfetmesi sebebiyle Dashibelov’un bu tezini eleştirmektedir. Bk. N. V. İmenohoev, "Drevniye Tyurki i Rannıye Mongolı: Problemı Etniçeskoy Atributsii Arheologiçeskiy Kultur Zapadnogo Zabaykalya”, Drevniye Kultur Mongolii Mongolii i Baykalskoy Sibirii (Materialı Mejdunarodnoy Nauçnoy Konferentsii 20-23 Sentryabrya 2010 g.), Edit. A. D. Tsybiktarov, (Ulan-Ude: İzdatelstvo Buryatskogo Gosniversiteta, 2010), 310.

31 Eremey Semenovich Gabyshev, Kult Solntsa V Mifologii Yakutov (Problema Drevnıkh Etnokulturnykh Paralleley), (Sankt-Peterburg: Avtoreferat Dissertatsii Na Soiskaniye Uchenoy Stepeni Kandidata İstoricheskikh Nauk, 1999), 17.

32 Seroşevsky, Saka Yakutlar, 41.

33 G. N. Rumyantsev, Rodoplemennoy sostav verkholenskikh buryat, Vyp. XII, (Ulan-Ude: Zapiski BMNIIK, 1951), 80; D. V. Tsybikdorzhiev, K Voprosı o proishojdeniyi etnonima Kurıkan, (Ulan Ude: Gumanitarnyye issledovaniya molodykh uchenykh Buryatii, 1996). 
kabileler de Kurıkanlara benzemiştir. Onların halefleri olan Saha/Yakutlar kuzeye doğru gelişleri ve zaman içerisinde yapılan evlilikler ile melezleşme oranı artmıştır. Pek çok Tungus sahaların yanında Sahaca konuşmaya başlamıştır. ${ }^{34}$

Kurumçi Kültürü'nü oluşturan Kurıkanların Türkçe konuştuklarını yukarıda da belirtmiştik. Okladnikov, onlardan kalan kaya resimleri ve runik yazıların en geç V-IX. yy. aralığına tarihlenebileceğini belirtmektedir. ${ }^{35} \mathrm{Bu}$ yazılardan iki tanesi Baykal yakınlarında AngaraLena Havzasında Murin Irmağı kolunda, üçüncüsü Kurtuhay şehri yakınlarındaki Yukarı Lena Nikolskiy kolunda, diğeri de Nukutah da keşfedilmiştir. ${ }^{36}$ Runik ve runiğe benzer bu yazılara (Resim 6-7-8) Yakutistan sınırlarında da ulaşılmıştır. Levin'e göre Orta Lena Havzası ve Pribaykal bölgesinde tespit edilen yazı sayısı $17^{\prime}$ dir. ${ }^{37}$ Levin, Yakutların atalarından kalan Runik yazıları ve tamga şekillerini atalarından yadigâr olarak XIV. Hatta XVII. yy.'a kadar kullandıklarını (Resim 9) da ifade etmiştir. ${ }^{38} \mathrm{Bu}$ yazıtların okuma önerileri için dil bilimci Levin'in makalesi oldukça önemlidir. ${ }^{39}$

Çin'e oldukça uzak bir bölgede yaşadıklarından haklarında çok fazla bilgiye tesadüf edilmese de çok iyi at yetiştirdikleri, başlarının deve başına benzediği, kaslarının ve kemiklerinin çok iri oldukları ve gün içinde birkaç yüz $l i$ hızla koşabildikleri, 5000 yetişmiş asker çıkarabilecek güçte oldukları, 647 yılında Çin sarayına elçi ve bu elçilerle birlikte yetiştirdikleri atlarından gönderdikleri gibi bilgiler edinmekteyiz. ${ }^{40}$ Bilge Kağan Yazıtı'nda düşman olarak zikredilen Üç Kurıkanlar çok büyük ihtimalle iyi savaşçılardı ki bu durumu onlara ait Lena Kaya resimlerinden (Fotoğraf 1) ve onlardan geriye kalan savaş aletlerinden, kurdukları müstahkemlerden ${ }^{41}$ ve günümüze kadar gelen şehir ve kalelerden ${ }^{42}$ de teyit edebilmekteyiz. Çin kaynaklarında dahi yetiştirdikleri atların güzelliklerinden bahsedilen Kurıkanların kaya resimleri de büyük oranda atlar ve atlı süvarilerden ${ }^{43}$ mürekkep olup (Resim 3), ana kompozisyon temasını ise av sahneleri oluşturmakta idi. ${ }^{44}$ Şişkin kaya resimlerinin bulunduğu alan ise hem kültt ${ }^{45}$ alanı olması hem de onlara ait kıymetli petrogliflerin bulunması bakımından önemli idi.

34 Seroşevsky, Saka Yakutlar, 58.

35 Okladnikov, Istoriyii i Kulturl Buryatii, 27.

36 Okladnikov, Ístoriyii i Kulturı Buryatii, 26.

37 G. G. Levin, "Lensko-Pribaykalskiye Runiçeskiye Nadpisi”, Karadeniz, (2014/21) 14.; D. D. Vasilev, Grafiçeskii Fond Pamyatnikov Tyurkskoy Pismennosti Aziatskogo Areala, (Moskva: İzdatelstvo Nauka, 1983), 23.

38 Levin, "Lensko-Pribaykalskiye Runiçeskiye Nadpisi”, 18.

39 Levin, "Lensko-Pribaykalskiye Runiçeskiye Nadpisi", 13-24.

40 Taşağıl, Çin kaynaklarına Göre Eski Türk Boylarl, 88-89.

41 A. V. Tivanenko, "Svyatilishcha Kurıkan Pribaykalya", Etnogenez i Kulturogenez v Baykalskom Regione (Srednevekovye), Edit. P. V. Konovalov, (Ulan-Ude: İzdatelstvo BNTS SO RAN, 2010), 215.

42 L. Gumilev, Eski Türkler, çev. Ahsen Batur (İstanbul: Selenge Yayınları, 2004), 338.

43 A. P. Okladnikov, Lenskiye Pisanitsı Naskalnlıye Risunki u Derevin Şişkino (İzdatelstvo Akademii Nauk SSSR, Moskvo-Leningrad, 1959), 51.

44 M. L. Vladimirovna, Korrelyatsiya i Periodizatsiya Petroglifov Verkhney Leny (Na Primere Shishkinskoi Pisanitsy), Vladivostok: Dissertatsiya Na Soiskaniye Uçenoy Stepeni Kandidata İstoriçeskiy Nauk DVO RAN, 2002), 17.

45 Tivaneneko, "Svyatilishcha Kurkkan Pribaykalya", 215. 


\section{Sonuç}

VII. yy. Çin kaynaklarından Xin Tangshu'da ve akabinde Türk tarihinin temel kaynaklarından Orhun Yazıtları'nın Kültigin ve Bilge Kağan abidelerinde adları zikredilen Ku-li-kan/Kurıkanlar Türk tarihi ve kültüründe çok önemli fakat bu öneme rağmen çok fazla bilinmeyen bir Türk boyudur. Öyle ki bu Türk boyu Türk tarihinin ve kültürünün neredeyse Amur'a kadar yayılmasına vesile olmuş. Yüzylllar boyunca Baykal ve ötesinde Türk dili ve kültürünün kendilerinin torunları olan Saha/Yakut Türkleri tarafından Baykal ve Baykal ötesi sahalara taşınmasına ve günümüze kadar kalmasına vesile olmuştur. Kurıkanlar Göktürklere bağlı olup hem Göktürklere hem de Çin'e oldukça uzak bir mesafede fakat korunaklı bakir bir sahayı kendilerine yurt tutmuşlardır. Baykal gölünün özellikle sol kıyısı boyunca Angara ve Lena nehirlerinin suladığı bereketli topraklarda hâkim olmuşlardır. Bölgeye gelişleri ile birlikte avcılık ve balıkçılıkla uğraşan yerel kabilelere hayvancılı̆̆ öğretmiş̧ler ve özellikle Türkçenin bu kabilelerin dillerine sirayet etmelerine sebep olmuşlardır. Baykal çevresinde ve Olhon Adası'nda arkeologlar tarafından Kurumçi Kültürü olarak adlandırılan dönem maddi kültür unsurlarını bırakmışlardır. Bu maddi kültür unsurlarından en önemlisi, onların Türkçe konuş̧uklarının ortaya konulmasının delili olan Türk runik harfli yazıtlardır. Bununla birlikte Kurumçi Kültürü'nün yayılım sahası içerisinde onlara ait mezarlar, mezarlardan elde edilen malzemeler, özellikle Şişkin köyünde tespit edilen Şişkin kaya resimleri ve onların yaşamlarından kesitler sunan tüm kaya resimleri, Baykal Gölü çevresinde bulunan gözetleme istihkamları onlardan kalan en önemli bakiyelerdir. Son olarak Türkçe konuştukları yazılı kaynaklar ve arkeolojik malzemelerle tespit edilen Kurıkanların günümüzde Moğol kabilelerinden biri oldukları zorlama bir şekilde literatüre sokulmaya çalışılmaktadır. Onların İslam kaynaklarında Kırgızlarla dil bakımından anlaşamadıkları ifade edilse de bu boy günümüzde Türkçe konuşan Yakutların atalarıdır ve Türkçe Yakutlar tarafından Türkistan'ın en kuzeyi sayılabilecek sahada onlar tarafından korunmuş ve günümüze kadar yaşamıştır.

Hakem Değerlendirmesi: Dış bağımsız.

Çıkar Çatışması: Yazar çıkar çatışması bildirmemiştir.

Finansal Destek: Yazar bu çalışma için finansal destek almadığını beyan etmiştir.

Peer-review: Externally peer-reviewed.

Conflict of Interest: The author has no conflict of interest to declare.

Grant Support: The author declared that this study has received no financial support.

\section{Kaynaklar/References}

Aristov, N. A. Türk Halklarının Etnik Yapısı. Çeviren Ahsen Batur. İstanbul: Selenge Yayınları, 2014.

Aseev, İ. V. Pribaykalye v Sredine Veka (po arheologiçeskim dannım). Novosibirsk: İzdatelstvo Nauka, 1980. Aydın, E. Orhon Yazıtları. İstanbul: Bilge Kültür Sanat, 2017. 
Bernştam, A. N. “Drevnetyurkskoye pismo na r. Lene”, Epigrafika Vostoka. (1951): 76-87.

Chavaness, E. Çin Kaynaklarına Göre Batı Türkleri. Çeviren. M. Koç. İstanbul: Selenge Yayınları, 2013.

Dashibelov, B. B. "Khunnu i Syanbi V Slozhenii Kulturı Khor1-Mongolov.”, Drevniye Kulturı Mongolii Mongolii i Baykalskoy Sibirii (Materialı Mejdunarodnoy Nauçnoy Konferentsii 20-23 Sentıyabrya 2010 g.). Ulan-Ude: İzdatelstvo Buryatskogo Gosniversiteta, (2010): 191-194.

Dashibelov, B. B. “O Hori Mongolah i Hordutah v Şamanskih Materialah M. N. Hangalova”, Etniçeskaya İstoriya i Kulturno-Bitovlye Traditsii Haradov Baykalskogo Regiona. İrkutsk: İzdatelstvo Ottisk, (2010): 54-60.

Dashibelov, B. B. Ístoki: Ot drevnih Hori-Mongolov v Buryatam Oçerki. Ulan-Ude: İzdatelstvo Buryatskogo Nauçnogo Tsentra SO RAN, (2003):

Dikov, N. N. Bronzovıy Vek Zabaykalya. Ulan-Ude: Akademii Nauk SSSR, 1958.

Gabyshev, E. Semenovich. Kult Solntsa VMifologii Yakutov (Problema Drevnıkh Etnokulturnykh Paralleley). Avtoreferat Dissertatsii Na Soiskaniye Uchenoy Stepeni Kandidata İstoricheskikh Nauk, Sankt-Peterburg: 1999.

Gumilev, L. N. Avrasyadan Makaleler I. Çeviren A. Batur. İstanbul: Selenge Yayınları, 2006.

Gumilev, L. N. Drevniye Tyurki, Sankt Peterburg: İzdatelskii Dom Kristall, 2002.

Gumilev, L. N. Eski Türkler. Çeviren Ahsen Batur. İstanbul: Selenge Yayınları, 2004.

Hudūd al-Ālam The Regions Of The World. Tran. And Exp. V. Minorsky. London: 1937.

İmenohoev, N. V. "Drevniye Tyurki i Rannıye Mongolı: Problemı Etniçeskoy Atributsii Arheologiçeskiy Kultur Zapadnogo Zabaykalya”, Drevniye Kultur Mongolii Mongolii i Baykalskoy Sibirii (Materiall Mejdunarodnoy Nauçnoy Konferentsii 20-23 Sentıyabrya 2010 g.). Ulan-Ude: İzdatelstvo Buryatskogo Gosniversiteta, (2010): 309-313.

İmenohoev, N. V. "Tipologiya drevneburyatskih Zahoronenii (k Problemam Etnogeneza Buryat)”, Etniçeskaya Ístoriya i Kulturno-Bıtovlye Traditsii Haradov Baykalskogo Regiona, İrkutsk: İzdatelstvo Ottisk, (2010): 21-32.

Kareyev, Ömürkul. Türkler ve Kăganlıkları. Çeviren Mustafa Kalkan. İstanbul: Bilge Kültür Sanat Yayınları, 2008. Kıldıroğlu, Mehmet, Kırgızlar ve Kıpçaklar. Ankara: Türk Tarih Kurumu, 2013.

Klyaştornıy, S. G. Kadim Avrasya'nın Bozkır Imparatorlukları. İstanbul: Tek-Esin Vakfı Yayınları, 2018.

Kocabekov, Muratbek. "Kırgızların Sayan-Altay Bölgesindeki Komşuları”, SDÜ Fen Edebiyat Fakültesi Sosyal Bilimler Dergisi (2015/36): 13-24.

Kozmin, N. N. "K Voprosu o Vremeni Vodvoreniya Buryat Okolo Baykala”, Sibirskaya Jivaya Starina, (1925/ III-IV): 113-128.

Ksenefontov, G. B. Uranghay-Sahalar Oçerki Po Drevney Ístoriyi Yakutov. T.I, İrkutsk: Ogiz, 1937, IX.

Levin, M. G. ve L. P. Potapov. Narodı Sibiri. Moskva-Leningrad: İzdatelstvo Akademii Nauk SSSR, 1956.

Levin, G. G. "Lensko-Pribaykalskiye Runiçeskiye Nadpisi”, Karadeniz, (2014/21): 14.

Levin, G. G. Istoricheskiye Svyazi Yakutskogo Yazıka s Drevnetyurkskimi Yazıkami VII-IX vv. (V sravnitelnosopostavitelnom aspekte s vostochno-tyurkskimi i mongolskimi yazıkami), Izd-vo SVFU, Yakutsk, 2013.

Okladnikov- A. P ve V. D. Zaporojegaya. Lenskiye Pisanitsı, Haskalnıye Risunki u Derevin Şişkino. MoskvaLeningrad: İzdatelstvo Akademii Nauk SSSR, 1959.

Okladnikov, A. P. “Drevnyaya Tyurkskaya Kultura v Verhovyah Lenı”, Kratkiye Soobşeniya XIX (1948): 3-11. 
Okladnikov, A. P. Ístoriyii i Kulturı Buryatii. Ulan-Ude: Buryatskoye Knijnoye İzdatelstvo, 1976.

Ögel, Baheddin. İslamiyetten Önce Türk Kültür Tarihi. Ankara: TTK, 2003.

Rigdılon, Ye. R. “K Drevnetyurkskim Runam Pribaykalya”, Epigrafika Vostoka VIII (1953): 86-91.

Rumyantsev, G. N. Rodoplemennoy Sostav Verkholenskikh Buryat. Vyp. XII, Ulan-Ude: Zapiski BMNIIK, 1951.

Seroşevsky, V. L. Saka Yakutlar. Çeviren A. Acaloğlu. İstanbul: Selenge Yayınları, 2007.

Soltonoyev, Belek. Kırgız Tarihi I-II, Çeviren M. Diykanbayeva. Ankara: Kömen Yayınları, 2018.

Şeşen, R. İslam Coğrafyacılarına Göre Türkler. Ankara: TTK Yayınları, 2001.

Taşağıl, A. "Yakutlar", TDV İA. 43, İstanbul: (2013): 295-296.

Taşağıı, A. Çin Kaynaklarına Göre Eski Türk Boyları. Ankara: TTK Yayınları, 2004.

Taşağıl, A. Göktürkler II. Ankara: TTK Yayınları, 1999.

Tivanenko, A. V. “Svyatilishcha Kurıkan Pribaykalya”, Etnogenez i Kulturogenez v Baykalskom Regione (Srednevekovye), Ulan-Ude: İzdatelstvo BNTS SO RAN, (2010): 205-229.

Tokarev, S. A. ve I. S. Gurviç. "The Yakuts", The People Of Siberia, Chicago-London: The University Of Chicago Press, (1964): 243-305.

Tsybikdorzhiev, D. V. K Voprosı o Proishojdeniyi Etnonima Kurıkan. Ulan Ude: Gumanitarnyye issledovaniya molodykh uchenykh. Buryatii, 1996.

Vasilev, D. D. Graficheskiy Fond Pamyatnikov Tyurkskoy Runicheskoy Pismennosti Aziatskogo Areala, Moskva: İzdatelstvo Nauka, 1983.

Vladimirovna, M. L. Korrelyatsiya i Periodizatsiya Petroglifov Verkhney Leny (Na Primere Shishkinskoi Pisanitsy. Dissertatsiya Na Soiskaniye Uçenoy Stepeni Kandidata İstoriçeskiy Nauk DVO RAN, Vladivostok: 2002.

Zoriktuev, B. R. “O Proishojdeniyi Horintsev”, Koçevyye Imperii Evrazii v Svete Arheologiçeskih $i$ Mejdictsiplinarnıh Isssledovanıyi. Edit. B. V. Bazarov, Kniga 2, Ulan-Ude, (2019): 47-151. 


\section{Şekil, Resim, Tablo ve Grafikler}

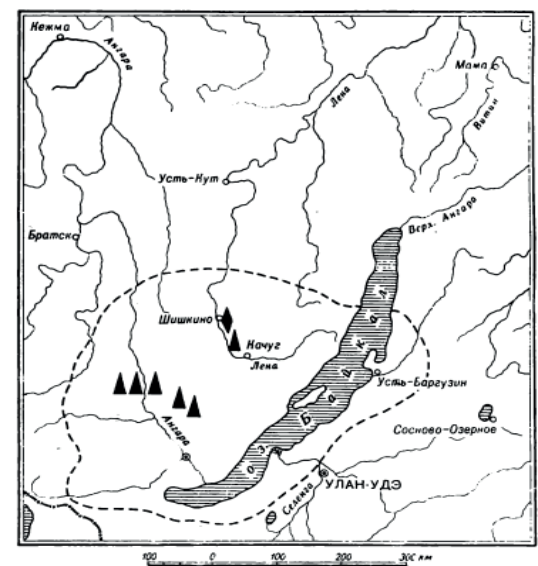

Resim 1: Baykal Gölü’nün batısında Lena ve Angara üzerinde Kurıkanlara ait kaya resimlerinin bulunduğu yerler. (Okladnikov-Zaporejagaya, Lenskiye Pisanitsl, Naskalnıye Risunki u Derevin Şişkino, 4).

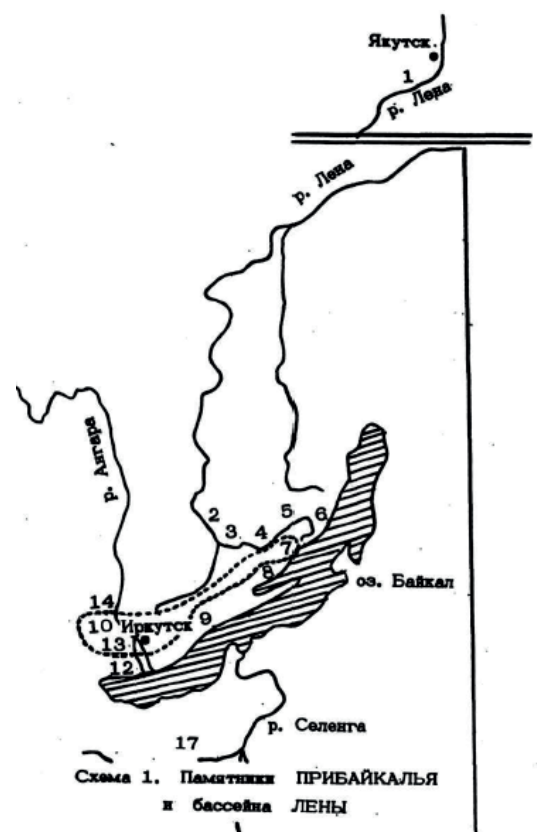

Resim 2: Türk Runik yazıların Baykal Gölü çevresinde tespit edilen konumları. (D. D. Vasilev, Graficheskiy Fond Pamyatnikov Tyurkskoy Runicheskoy Pismennosti Aziatskogo Areala, 88) 


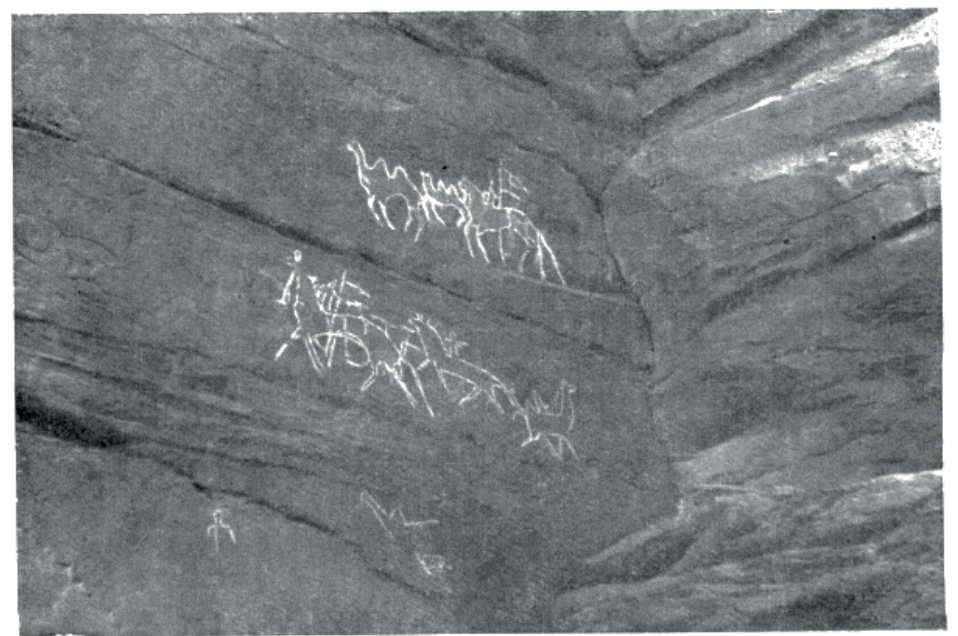

Resim 3: Kurıkan Atlı Süvarileri. (Okladnikov-Zaporejagaya, Lenskiye Pisanitsı, Naskalnıye Risunki u Derevin Şişkino, 51).
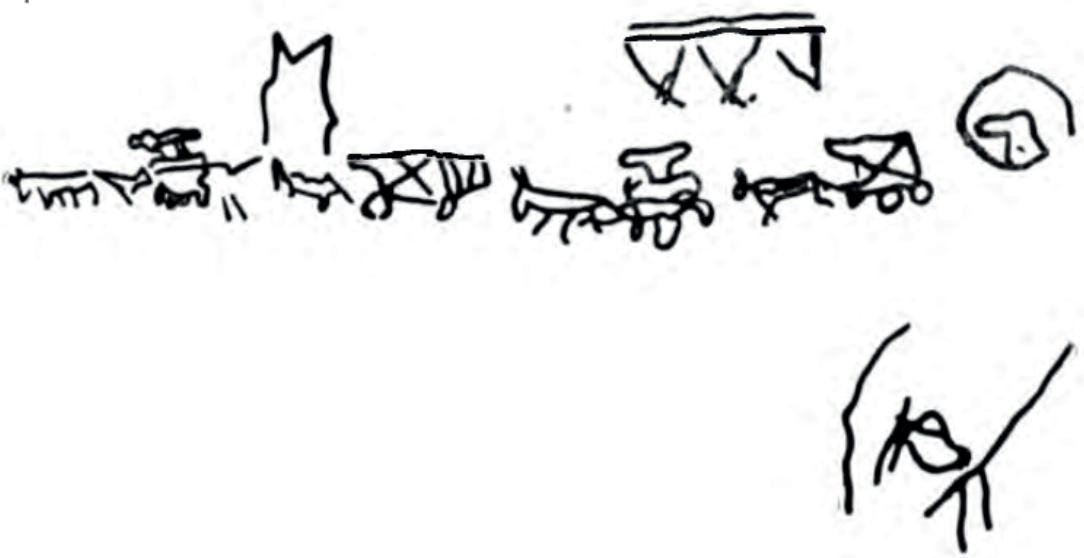

Resim 4: Kurıkanların Şişkin kaya resimlerinden göç sahnesi. (Okladnikov, İstoriyii i Kulturı Buryatii, 216). 


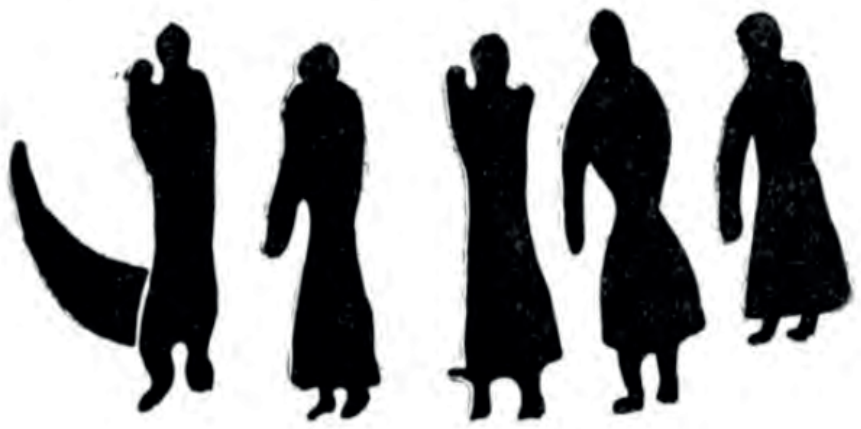

Resim 5: Kurıkanların Şişkin kaya resimlerinden yaya insanlar (Okladnikov, İstoriyii $i$ Kulturl Buryatii, 291.).
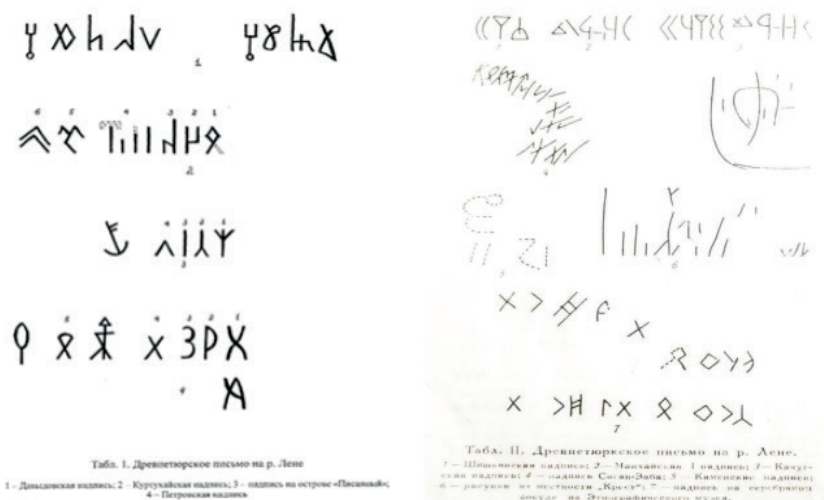

$x>A r \times \& \diamond>\lambda$

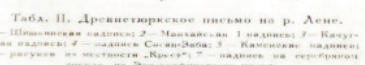

Resim 6: Lena'da tespit edilen Türk Runik yazıları. (A. N. Bernștam, "Drevnetyurkskoye pismo na r. Lene", Epigrafika Vostoka. 1951, T. IV, No: 6, 76-87.) 

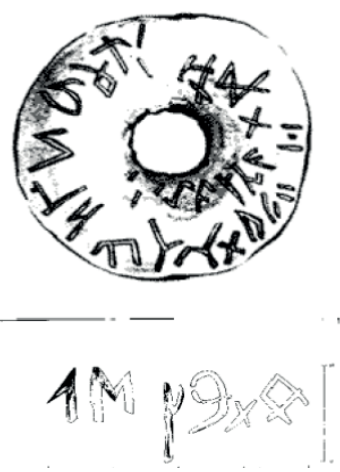

Resim 7: VII-X arasına tarihlendirilen Lena-Baykal bölgesinden ağırşak üzerine Runik yazı. (Levin, "Lensko-Pribaykalskiye Runiçeskiye Nadpisi", 23.).

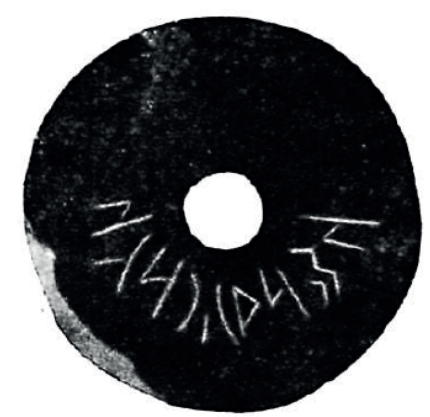

Resim 8: Olhon-Aymak'da keşfedilmiş Runik yazılı ağırşak (Ye. R. Rıgdılon, “K Drevnetyurkskim Runam Pribaykalya”, Epigrafika Vostoka, VIII, M-L, 1953, 87)

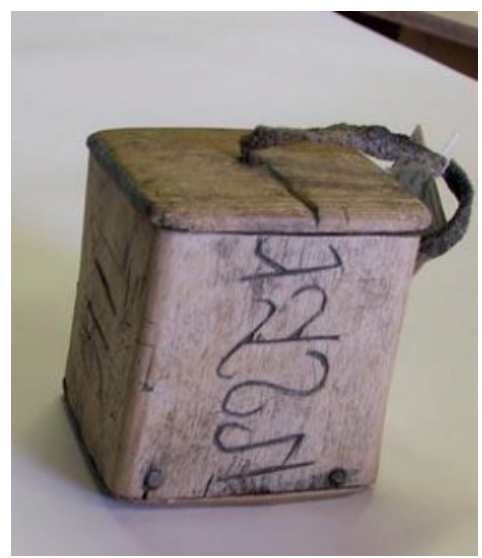

Resim 9: Tanımlanamamış XIII-XIX yy. arasına tarihlendirilmiş Suntar Ulus'tan enfiye kutusu üzerindeki Runik benzeri işaretler. (Levin, "Lensko-Pribaykalskiye Runiçeskiye Nadpisi”, 21). 